\title{
Impact of a Fashion fTRACE App on the Perception of Sustainability
}

\author{
Jochen Strähle $^{\mathrm{a}}$, Franziska Girwert ${ }^{\mathrm{b}}$ \\ ${ }^{\mathrm{ab}}$ International Fashion Management, Reutlingen University, Reutlingen, Germany
}

\begin{abstract}
2016Research Leap/Inovatus Services Ltd.

All rights reserved.

Keywords:

Customer perception

Sustainability

Customer behavior

Multichannel

QR-Code

Information searching

Transparency

Traceability

The purpose of this paper is to examine the relationship between the consumers' perception of sustainability and the application of a QR-code in stores with the focus on the information searching behavior regarding sustainable aspects. An online questionnaire was conducted with fashion students at Reutlingen University: in total, 65 students participated in the survey. Paired samples t-test and other statistical analyses were applied to test research questions. Apart from this, the research paper is based on a literature review. Furthermore, the decision was taken to use a projective method in the form of a dummy fashion fTRACE website. Key findings of the survey are that participants give sustainable aspects a higher importance with a QR-code than without one. Participants who prefer a product with detailed information experience a "positive shopping feeling" when provided with transparency via a QR-code. "Origin", "production" and "quality" were rated of higher importance by those participants. These findings suggest that, transparency provided through the application of a QR-Code in stores influences the consumers' perception of sustainability. Due to the small sample size of participants (65) in the study, findings of this research not generalizable to a larger population. This paper focused on the consumers' information searching behavior regarding sustainable aspects, limiting its findings to impacts on perception of sustainability. Further research is therefore recommended.
\end{abstract}

\section{Introduction}

"I created the brand because transparency was what I was looking for as a consumer but couldn't find. I'm using it as a tool for change. [...]" (Borromeo, 2013). This statement by the Belgium fashion designer Bruno Pieters demonstrates the need for providing more information to the consumers. Many fashion brands' primary purpose still is to maximize profit and to produce clothes in low-waged countries without providing information about their activities along the supply chain (Payton, 2013). Therefore, a development towards greater transparency is indispensable. The question arises, how companies are able to implement greater transparency along the entire value chain and what kind of information regarding sustainable aspects consumers are searching for in fashion products. As consumers become more aware of sustainability, they also expect detailed product information provided by companies (Liegl, 2014). Therefore, the issues of sustainability and transparency in fashion business are a topic of major debate in contemporary research. The paper addresses the specific research objective to investigate the relationship between consumers' perception of sustainability and the information searching behavior regarding sustainable aspects. In order to gain a profound understanding of transparency provided by a fashion fTRACE app and its impact on perception of sustainability a survey was conducted, which addresses the following research objectives:

- to compare the consumers' degree of importance for information searching regarding sustainable aspects in general with and without a QR-code (Quick Response Code)

- to examine the consumers' degree of importance for information searching regarding sustainable aspects with a QR-code when preferring a product with detailed information
- To investigate the impacts of transparency provided by a QR-Code on consumers' perception of sustainability when preferring a product with detailed information.

The method chosen to give an insight at the beginning of this paper is a literature review providing an overview of the state of the art concerning sustainability and the multichannel environment as well as regarding transparency and traceability in the fashion industry. The literature review is based on different sources ranging from books to scientific research papers to find appropriate academic findings. Furthermore, a projective method in form of a dummy fashion fTRACE website was used serving as a basis for the survey and visualizing the application of a QRcode in stores. An online questionnaire was conducted with 65 fashion students at Reutlingen University to examine how a QRCode helps to ensure greater transparency. A paired sample t-test, an independent t-test and a chi-square test were applied to test the research objectives.

The second chapter firstly deals with the definition of the terms sustainability and sustainable fashion followed by the importance of the issue in today's society. Afterwards the consumers' perception of sustainable fashion and their information demand will be demonstrated in order to find out the consumers' knowledge, attitude and behavior toward sustainability. The following chapter commences with a description of the multichannel-environment and its importance for the retail industry before the changing customer behavior will be explained. After that, the information searching behavior in general and via smartphone will be described, followed by the consumers' buying decision-making process. The next chapter provides background information about the fTRACE app as wells 
as its functionality compared to similar apps. Additionally, the current situation of transparency and traceability in fashion business as well as best practice examples are shown. At the end of this chapter the dummy fashion fTRACE app will be explained, on which the online questionnaire is based. The last chapter of this research paper analyses the online questionnaire in order to examine the impact of transparency on consumers' perception of sustainability through the application of a QR-Code in stores. A subsequent discussion refers back to the research question. Finally, conclusions and recommendations summarize all gained findings of this research paper.

\section{Literature Review}

\subsection{Sustainable Fashion}

In order to assess the consumers' perception of sustainable fashion it is important to begin with the definition of the terms sustainability and sustainable fashion. In 1987 the most common definition of sustainable development was published by the "World Commission on Environment and Development" (WCED) in "Our Common Future", also known as the Brundtland report. The report describes sustainable development as "development which meets the needs of the present without compromising the ability of future generations to meet their own needs." (Drexhage \& Murphy, 2010). Since the "United Nations Conference on Environment and Development" (UNCED) 1992 in Rio de Janeiro, the term sustainable development was given political salience (Drexhage \& Murphy, 2010).

Sustainable fashion can be defined as fashion clothing that is produced with a longer product life cycle under fair trade conditions. Furthermore, a sustainable fashion concept considers a local and ethical production system as well as eco-friendly or recycled materials to avoid destroying the environment or exploiting workers (Fletcher, 2008; Joergens, 2006). Often the terms "green fashion" and "ethical fashion" are used in the same context as sustainable fashion. While "green fashion" focuses on the utilization of recycled materials and biodegradable fibers, "ethical fashion" mainly relates to produce under fair labor conditions (Shen, Richards, Lui, \& Feng, 2013). "Both of these dimensions together make the sustainable fashion concept more comprehensive and richer in scope" (Shen et al., 2013).

In times of globalization, climate change and increasing environmental problems, facing sustainable issues has become more and more important, which also affected the fashion and textile industry (Jefremow, 2013). Widespread and unending information through digitalization, strengthens the customers' awareness of social and environmental disasters in the fashion industry (Bhaduri \& Ha-Brookshire, 2011; Williams \& Page, 2011). This underlines the impact of sustainable fashion on consumers' perception and purchase behavior, which will be shown in the following chapter.

\subsection{Customer Perception of Sustainable Fashion}

Firstly, it is necessary to examine how customers define and what they know about the social and environmental side of sustainability in the apparel industry. A study by Shen et al. (2012) has found that consumers want to support sustainable fashion businesses and are willing to pay a higher price for it, but they have a lack of knowledge about this issue. Further, this study has shown that nearly $90 \%$ of the participants had never purchased ethical fashion nor they had knowledge of buying it. Additionally, they could not name any ethical fashion brand (Shen et al., 2012). "This result indicates that ethical fashion apparel has not been well promoted" (Shen et al., 2012, p.238). Even in 2015, only five percent of consumers feel knowledgeable about ethical fashion and textile brands (Thieme, 2015). According to Hill (2012), the majority of young consumers define sustainability in general as creating durable products. Concerning the apparel industry, long-lasting products, economic health of the business and environmental concern were perceived as the most important issues by respondents (Hill Hyun-Hwa Lee, 2012). Interestingly "wash care and laundering" was listed as least important sustainable practices by respondents (Hill Hyun-Hwa Lee, 2012). However, this factor has a main environmental impact on the apparel industry, which further shows the consumers' lack of knowledge about impacts on the environment (Allwood, 2006; Hill Hyun-Hwa Lee, 2012). Hill's study also shows the link between knowledge and its perceived effectiveness, which means how provided information can influence the way consumers perceive something as important (Dickson, 2000). The more knowledge they have on a specific issue, the more they perceive it as important (Hill Hyun-Hwa Lee, 2012). Regarding Kozar's and Hiller's Connell (2013) study, respondents felt more knowledgeable about environmental issues than on social issues concerning the apparel industry (Kozar \& Hiller Connell, 2013). Contrarily, Shen et al. found preventing sweatshop labor is more important to consumers than protecting the environment, despite the fact that they had little knowledge on the sweatshop situation (Shen et al., 2012). This demonstrates, on the one hand, limited knowledge and misconception of consumers regarding sustainability, since they define it simply without describing it in detail or with examples (Carew \& Mitchell, 2002; Gam \& Banning, 2011). On the other hand, consumers' perception of importance for certain sustainable issues differs with regard to the respondent sampling group. Therefore, these findings are not generalizable, since different target groups have different needs. Hence, companies have to acquire an understanding of their customers' attitudes and communicate the value of sustainability in order to build trust (Thieme, 2015).

Studies also show, that even though consumers have in general a positive attitude toward sustainable products, they finally do not apply this attitude into ethical fashion consumption (Niinimäki, 2010; Solomon \& Rabolt, 2004). One reason for this so called attitude-behavior gap could be based on the high amount of fashion products produced in developing countries which results in uncertainness by consumers. This indicates that the more information is provided, the more knowledgeable consumers are, the better they can make ethical judgments and buying decisions (Joergens, 2006). By increasing transparency of production and manufacturing processes, companies ensure more confidence for purchasing sustainable products. Through their goodwill and reputation in terms of sustainability, consumers' are more likely to alter their attitudes and behaviors. Subsequently, this results in a greater awareness of sustainable products and sustainability (Shen et al., 2012.). In order to close the attitude-behavior gap the provided information has to satisfy the factors of appropriate content and timing (Thøgersen \& Schrader, 2012).

\subsection{The Multichannel Environment}

\subsubsection{Changing Customer Behavior}

Due to technological developments and increasing consumer information demand, multi-channel-retailing is currently the most important (r)evolution in the retail business (Spannuth, 2012). Neither in literature nor in practice, can a consistent definition of "multi-channeling" be found. However, it can be described as the 
parallel application of different sales channels without considering channel integration. One step further takes it the concept of "cross-channel-retailing", which consistently links all channels together and creates a seamless shopping experience. "Omni-channel-retailing" means when consumers are able to apply all channels parallel through the complete integration in each buying stage. Customers are enabled to switch between all channels at any time, e.g. scanning a barcode of a retailer at the POS in order to obtain further product information (SchrammKlein et al., 2014).

In times of the internet, consumers can decide where and when they want to make a purchase. Due to the fast expansion of the internet, the online commerce is one of the channels with the highest potential. While the e-commerce sales volume has more than triplicated from 12 billion $€$ in 2007 to 38 billion $€$ in 2013, the growth in sales of physical stores is less than one percent. However, the German stationary retail with sales of 457 billion $€$ in 2014 still represents an important purchase channel. Furthermore, stationary retailer who also sell their products online are with more than $30 \%$ of the online sales volume an important online-player (Reinartz, 2015). Also, the sales volume generated through mobile commerce is expected to increase from $20 \%$ of online retail sales in 2014 to more than $30 \%$ by 2020 (Heinemann \& Gaiser, 2015).

With regard to the German market, three out of four consumers use the internet; $73 \%$ of them make purchases in online shops (Reinartz, 2015). Almost every person under the age of 29 has a smartphone. $20 \%$ of these consumers purchase via their smartphone, $90 \%$ at least once a month. In contrast, $60 \%$ of the silver surfers have a smartphone, whereof only $4.4 \%$ buy a product with their smartphone (ECC Köln, 2015). While more than one third of the young online shoppers search for information via their smartphone, only $7 \%$ of the silver surfers do it, since they are scared of insufficient data security (ECC Köln, 2015). Every sixth online purchase is executed through impulse buying, which emphasizes the importance of emotions and inspiration given in online retailing (ECC Köln, 2015).

More than $50 \%$ of the German population see themselves as traditional stationary retail shoppers, while smart natives prefer both online and offline shopping (65\%). Almost $70 \%$ of them find "instore-return" of products, which have been purchased online, very important. Online and offline redeemable "coupons and special offers" are also very relevant, followed by "online notification of product availability" in stores (ECC Köln \& hybris $\mathrm{GmbH}$, 2014). 58\% welcome "same day delivery" and digital service promotions e.g. smartphone apps in stores in order to gain product information (INTERNET WORLD, 2015).

Consumers expect consistent Omni-channel-services in order to switch from one channel to another one during the buying process (Schramm-Klein et al., 2014) Therefore offline- and online-channels have to be linked to each other such as to satisfy the consumers' needs and their growing information demand (Bruce, 2012). While two out of three online retailers use several channels, online pure player represent $30 \%$ of them. More than $60 \%$ of the Top-1000-online retailers optimized their online shop for mobile devices, which shows that the mobile sales channel, in addition to other channels, is yet very important (EHI Retail Institute \& Statista GmbH, 2015). Because the sales of the offline channel will decrease in the future, many retailers invest in attractive in store designs. But as mentioned before, the customer wants both: online and offline shopping. Therefore, $50 \%$ of the 1000 biggest online shops in Germany run a physical shop as well. More than $40 \%$ of these shops implemented "Click \& Collect" as well as "in store-return - and order". With the aid of "Click \& Collect" more than $65 \%$ of these retailers generate a growth in sales of almost $20 \%$ through impulse buying (EHI Retail Institute, 2015). Additionally, multi-channel-customers are more profitable for retailers, since they spend almost $30 \%$ more than single-channel-customers (Thomas \& Sullivan, 2005; TSystems, 2013; Venkatesan, Kumar, \& Ravishanker, 2007).

\subsubsection{Information Searching Behavior}

Consumers research online in order to purchase afterwards offline, also known as the "ROPO-Effect", which shows how strong both channels influence each other. $48 \%$ of all online researched fashion products where purchased offline, whereof $11.7 \%$ are based on researches through the online-shop of the same supplier; these purchases made up $17.2 \%$ of the sales volume in physical stores. The interdependency is even more distinctive between online researches and purchases via print catalogs (29.9\%), which generated $35.2 \%$ of the sales volume of printed catalogs (Bruce, 2012; Zaharia, 2012).

Another study shows, that nearly $40 \%$ of respondents indicated to research online first and then purchase in stores. The priorranking ways for information search are search engines (80\%) and large shopping platforms e.g. Amazon (72\%), followed by price comparison sites (48\%) in 2014. In contrast, apps are used only by one-fifth. $68 \%$ of respondents already used their smartphone for product information searches at the POS in 2014. Aspects such as price (92\%), availability (80\%), followed by product features $(86 \%)$ or consumer ratings $(69 \%)$ have been ranked higher than aspects regarding sustainability $(47 \%)$ by those respondents. However, $83 \%$ of respondents would like to receive more detailed information on product features concerning local offers (Heinemann \& Gaiser, 2015) Also, GS1 Germany found out ,that nearly half of consumers prefer a product when provided with detailed information (GS1 Germany, 2013). Since $45 \%$ of consumers perceive barcode scanning as the greatest improvement to obtain further product information, provided information needs to be reliable and trustworthy (GS1 Germany, n.d.). This shows how little attention sustainability is paid to by consumers, compared to other aspects. Providing reliable information could create awareness of giving sustainable aspects a higher importance and therefore ensures customers to pay more attention to sustainable aspects.

As mentioned before consumers research online for product information and price comparisons in order to purchase afterwards offline. Technological developments lead to unending information provided through the internet, whereas the classical buying-decision process changed strongly. Figure 1 demonstrates the steps of the classical buying-process, where consumers select and purchase products of the same supplier. Here the "Point of decision" (POD) takes place at the "Point of Sale" (POS).

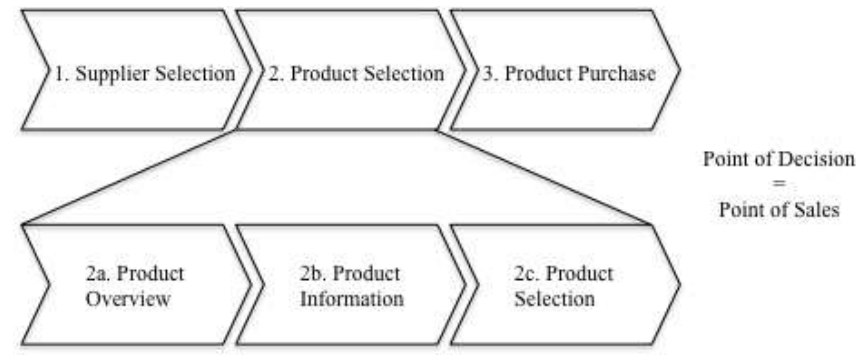

Figure 1: The classical Buying-Decision Process (Gherkins \& Bergsma, 2013) 
Comparing the new online buying-process (figure 2), caused by technological developments, consumers firstly select a product on the internet. With the aid of e.g. company websites or customer reviews, which are the most trustworthy source for consumers, consumers compare these products based on product information and then select a product. Afterwards, they choose the supplier, where they buy the product. The new online buyingprocess illustrates how uncoupled from offline and online channels a consumer can decide. Due to the high amount of product offers and information on the internet he decides mostly price-orientated, whereby the POD becomes more and more important (Heinemann \& Gaiser, 2015). Consumers benefit from a unique shopping experience, flexibility and simplicity to a greater extent while switching back and forth between information, buying and communication channels (Heinemann \& Gaiser, 2015).

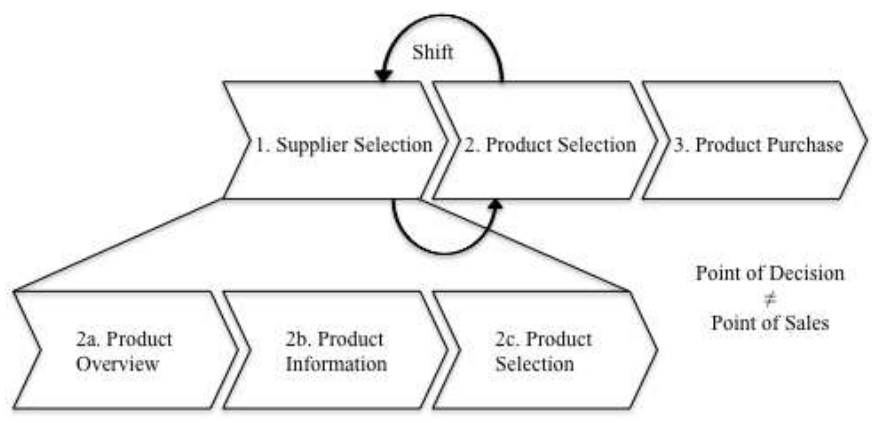

Figure 2: The new Online Buying-Decision Process (Gherkins \& Bergsma, 2013)

In summary, without considering online activities in stationary retail and therefore creating a positive shopping experience for consumers, companies will not have a chance to survive in the cutthroat competition. A huge challenge will be to hold the consumer in his sales channel during the buying-process, so that he will not switch to another one of a competing retailer (Rittinger, 2014). Since consumers make more use of their smartphones during buying-processes, boundaries between offline and online channels become increasingly blurred (Rittinger, 2014). Therefore, changing consumer and information searching behavior as well as market data speak for a retail concept with a multi-channel approach (Reinartz, 2015).

\section{From fTRACE app to fashion fTRACE app}

The following chapter firstly provides background information about the fTRACE app as wells as its functionality compared to similar apps. Furthermore, it refers to transparency and traceability in fashion business. Finally, the dummy fashion fTRACE app will be explained, whereon the following survey is based on

\subsection{FTRACE app - Information and Functionality}

Nowadays consumers are more aware of their purchased products and ask for detailed information e.g. the origin of a product. Therefore traceability along the value chain plays an increasingly important role (Liegl, 2014). FTRACE is an app providing consumers with the opportunity to trace food products along the value chain in order to gain detailed information about the origin, processing and quality as well as recipe tips. By means of pictures, videos or a map of the factory consumers gain a deeper insight of the processing. Each fTRACE product is provided with a QR-code on the packaging, where information can be scanned with a smartphone or by entering a number code on the website.

Through fTRACE the value chain is more transparent which creates more trust among consumers. Thereby, it is possible that consumers prefer a product which is provided with a fTRACE code to another one (Liegl, 2014). However, the Verbraucherzentrale Hamburg recently found out that the degree of traceability for fTRACE products is acceptable. That means their products can be traced until the country of production, but not back to the very end of the supply e.g. a precise defined region (Verbraucherzentrale Hamburg, 2015). Also contradictory information provided by the app or missing wireless communication in stores has been observed (Meßing, 2014). More than 100 manufacturers and retailers are labeled with the fTRACE code, through which consumers can trace meat, poultry, fish, fruit and vegetables (fTRACE, 2015b). In fact, labeled vegetables and fruits are hardly found in supermarkets even though fTRACE states this on their website. In addition they should consider a greater and consistent labeled product range. For instance, some products of the label Meine Metzgerei, a meat manufacturer and one of their partners, are provided with a fTRACE code, others not. Therefore it is hard for customers to compare products directly or to make better buying decisions. Compared to similar apps such as Codecheck or barcoo, fTRACE focuses on the essentials, which is providing detailed information. Metroprotrace, an app which is operated by the trading concern Metro AG, additionally offers a modern and appealing user interface. Both Codecheck and barcoo mainly provide information which links directly to a company's website and not specifically to a product as it does at the fTRACE app.

In summary, fTRACE needs to oblige their partners to make transparency a prerequisite. It is important that the provided information is correct, consistent and available in stores at any time. If these factors are not met, this will cause distrust in the consumers. After all, the majority of consumers welcome digital services in stores such as the fTRACE app (INTERNET WORLD, 2015).

\subsection{Transparency and Traceability in Fashion Business}

The "Rana Plaza"-disaster in a Bangladesh factory, were more than 1000 workers were killed through the collapse of a building, has strengthened an increased demand towards a greater transparency (Borromeo, 2013). Especially consumers expect more detailed product information provided by companies (Liegl, 2014). Through new technologies such as smartphones consumers increasingly use the internet in order to search for information. However, provided information through apps need to be available, correct and trustworthy. Consumers will not use again those apps that do not meet these prerequisites and subsequently switch to another brand (GS1, 2011). It is also important to communicate sustainable performance in such a way that provided information is complete, comparable and comprehensible so that consumers clearly understand a company's purpose (Confino, 2014). However, more than $90 \%$ of brands don not know where their raw materials come from, not to mention where their clothes are made (61\%) (Gould, 2014). Many fashion brands' primary purpose is to maximize profit and to produce clothes in low-waged countries (Payton, 2013). Hence, they do not provide information about their activities along the supply chain. Due to complex supply chains and fragmented production process into several countries, traceability is still a big challenge (Niinimäki, 2015). 
Therefore, companies have to consider a few factors in order to enable a greater transparency. Some of them are willing to invest extra money in order to ensure fair and safe working conditions. But they have to communicate costs of a product to consumers to make them understand what the price is based upon in order to perceive a value. Only then consumers are willing to pay a higher price. It is not only a company's liability to take action; consumers should also question how their clothes were produced. Apart from the retailer and consumer, garment workers should have the chance to influence their working conditions as well (Gould, 2014). Therefore, all stakeholders have to be integrated in the process of transparency and traceability. Everyone from garment workers to customers should be informed about a company's practices and take action in order to enable a greater transparent apparel supply chain (Radhakrishnan, 2015). Also the use of technology is helpful to ensure transparency. Through e.g. e-learning platforms workers are involved and informed in the whole process. Other programs give them the opportunity to rate a factory's performance (Gould, 2014). In 2012 the USdepartment store Macy's has launched a RFID-Technology (radio frequency identification). With the aid of RFID, products can be identified along the value chain. Other advantages such as accuracy of the stock, which also leads to reducing losses, increase of turnover, same day delivery and therefore most importantly customer satisfaction can be achieved (Howe, 2015). A new technology named Blockchain, an open source database, enables consumers to inform themselves about ethical standards of their products. Decentralization of the data, which means that no one is able to control what kind of data is shown, will also bring more transparency into complex supply chains (Steiner, 2015).

Transparency can only build trust among consumers, if provided information is correct, long-lasting and objective. Therefore it is also necessary to publish negative results or information about breaches in order to be credible. Otherwise, those companies who pretend to be sustainable but do not undertake any appropriate activities, are as accused of "greenwashing" (Niinimäki, 2015). Through negative experiences or misleading information, consumers remain skeptical toward a company's social and environmental activities (Bhaduri \& Ha-Brookshire, 2011; Williams \& Page, 2011; Thieme, 2015). Regarding transparency as a liability or marketing tool only will reduce a company's competitive advantage, which will subsequently entail the loss of the consumers' trust (Young, 2013). Additionally, values and sustainable principles have to be implemented holistically in their corporate culture which means at all levels, functions and processes (Niinimäki, 2015). Consequently transparency is achievable on a global scale, when it is in demand by both companies and consumers (Gould, 2014).

Honest by e.g. is the pioneer of those companies who seek for $100 \%$ transparency in the fashion business. They perfectly show how to link sustainable and transparent issues. Consumers get deep insight from yarn origin to manufacturing details. They offer environmentally friendly and fairly produced products with detailed information about where their clothes were made, by whom and how the price of the product has been calculated (Honest by, n.d.). Also Everlane shares a full cost breakdown of its products by showing their markup compared to traditional retailers. Additionally, they tell a story and show pictures behind each factory (Morton, 2015). As they claim to offer a "radical transparency" they ask their customers to always questioning a company's practices, e.g. production processes (Everlane, n.d.). Reformation, a fashion brand based in Los Angeles, produces mostly in their own factory. They implement sustainable practices throughout their core business such as the usage of recycled hangers and packaging, renewable energy as well as sustainable and vintage fabrics. Further, they show customers the environmental impact of each purchased item and remind them to take care of their clothes (Reformation, 2015). Zady shows pictures and videos behind each product so that customers are able to discover the whole production process. This creates emotions, which is often missing in online shopping. By learning more about each item they think differently about it and subsequently change their buying behavior (Morton, 2015). Zady's mission is to raise awareness of purchasing more highquality products by showing their customers the environmental impact of low-quality products. Subsequently they perceive and understand the quality of products and its value even better (Zady, 2015). All these fashion brands are perfect examples of how transparency and traceability can be implemented across the whole supply chain while building connections to customers (Morton, 2015).

\subsection{Dummy fashion fTRACE App}

In 2014, the majority of consumers already used apps in order to search for product information (Heinemann \& Gaiser, 2015). However, currently there is no app for the apparel and fashion industry, enabling consumers to trace detailed information about sustainable aspects of products. Therefore, by means of the website generator jimdo (n.d.), a dummy fashion fTRACE website (2015) has been created for this study. Such an app may be helpful to satisfy the consumers' demand for detailed information by combining sustainability and traceability with mobile technology at one place. It forms the basis of an online survey conducted with fashion students, which will be explained in the next chapter. Pictures of the website have been attached in the survey. They visualize the scanning process of a QR-code in stores in order to get an idea of how detailed product information regarding sustainable aspects on such a fashion fTRACE app can look like. The QR-code has been created through a QR-code generator. In such an app, detailed information about the following sustainable aspects is recommended: product information, origin, production, quality and price calculation as well as wash and care advices. Through pictures and videos of manufacturer as seen by Zady, consumers could gain deeper insight of the production process. Only when manufacturers provide detailed information about their origin, such as maps of their address or a precise defined region, consumers exactly know where their clothing was made. Additionally, pictures of workers can show consumers by whom their item was manufactured and therefore increases the company's credibility and trustworthiness. Also certificates by recognized institutions as well as quality seals are a prerequisite for manufacturer, which enable greater transparency. Consumers have the right to know how the retail price of a product has been calculated. Therefore, a full cost breakdown as seen by Honest by, can give consumers the opportunity to understand the exact price composition. Further, information regarding wash and care advices are attached as to remind consumers to also take care of the environment by using e.g. appropriate detergents. With the aid of the fashion fTRACE app, consumers are connected to their purchased products by having an idea of the environmental and social footprint (Confino, 2014). Additionally, QR-codes are a huge advantage for retailers since they are not only affordable and competitive, but they also link several channels with each other (Schramm-Klein et al., 2014). Fig. 3 demonstrate examples from the app. 


\section{PRODUKT XYZ}
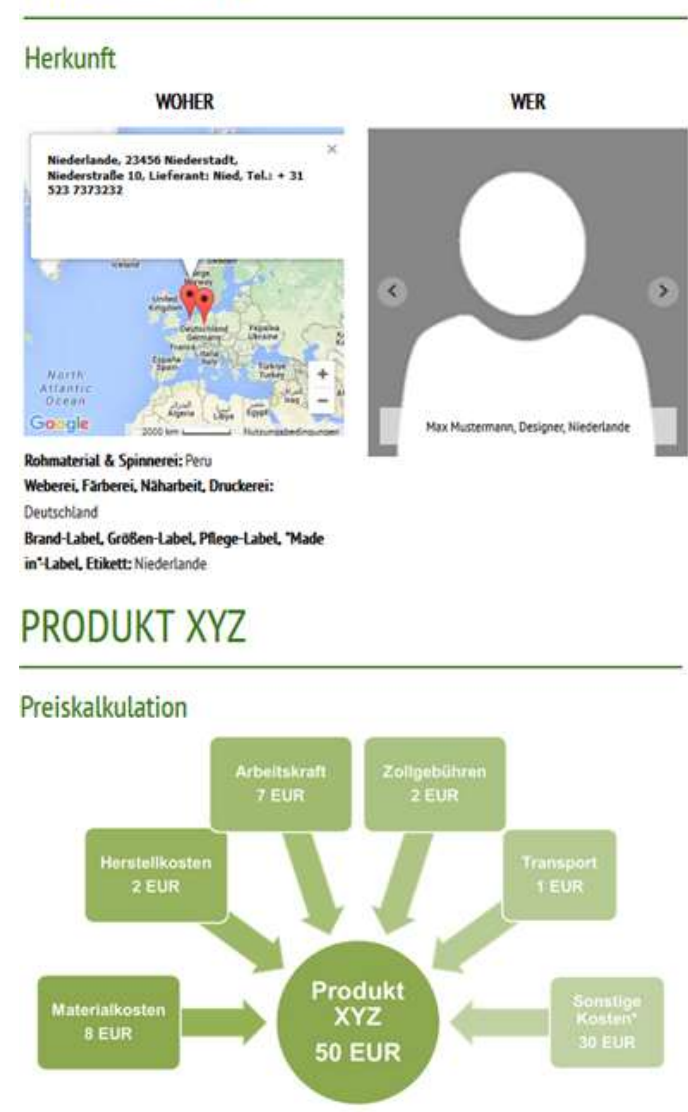

Wit glabben Sie als Endverbraucher haben das Recht zu effahren, wie der Verkautspees des Produktes entstanden ist.

- Sonstige Kosten: Wholessele Mark Up (Gewinnaufschlag GroShandel) und Retail Mark up (Gewinnaufschlag

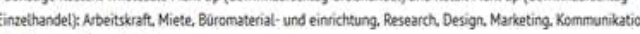
Versicherung, Transport u.A.

Figure 3: Example place of origin and price calculation from the dummy fashion ftrace app

\section{Empirical Analysis}

\subsection{Aim of the Study}

The study was undertaken in order to find out how consumers perceive transparent information through a QR-Code and whether they prefer a product with detailed information compared to a similar product without the same. The purpose of this survey was to examine the impact of transparency on perception through the application of a QR-Code in stores. The study addressed both the information searching behavior in general (without a QR-code) and by using a QR-Code, as noted in the following research questions:

- What is the consumers' degree of importance for information searching regarding sustainability in general compared to the application of a QR-Code in stores?

- What is the consumers' degree of importance for information searching regarding sustainability through the application of a QR-code when preferring a product with detailed information?

- What kind of relationship can be identified between the preference for a product with detailed information and the impacts of transparency provided by a QR-Code on consumers' perception of sustainability?

\subsection{Methodology}

The study is descriptive and the results are based on primary data. An online questionnaire with 65 respondents was conducted receiving an email containing a link to the survey. Participants were a sample of undergraduate and graduate students enrolled in the School of Textiles and Design (TD) at Reutlingen University. Respondents were required to answer 14 questions. Amongst others a five-point Likert-scale was used measuring the degree of importance for information searching in general and through using a QR-Code; "1" represented "very important" and "5" represented "completely unimportant". To visualize the utilization of a QR-Code in fashion retailing pictures were attached in the survey (see figure 10 in the appendix). They show how product information regarding sustainable aspects as well as transparency can be transferred on an app in detail as described in the previous chapter. Respondents were also asked to answer multiple response and single selection questions in order to examine the impact on their perception of transparency as well as their preference for a product with detailed information. Additionally, the survey examined factors according to gender, age, purchase channel and information channel as well as the degree of importance for purchase aspects. It also included the purchase behavior of sustainable clothing and whether participants already used a QR-Code in stores. To provide an overview of the sample, descriptive statistics were performed on the demographic variables as well as on the purchase channel and its aspects. Multiple responses cross tabulation were used in order to find out how the purchase and information channel relate to each other. A paired sample (dependent) t-test and independent t-test were used to test the first two research questions. Finally a chi-square test was performed to test the relationship between the preference for a product with detailed information and the impact on consumers' perception of sustainability.

\subsection{Results}

A total of 65 respondents participated at this study, whereas females represented the majority with $86.2 \%$. The mean age $(58.5 \%)$ of the sample was 21 to 25 years. More than $60 \%$ of the mean age group were females. Participants were asked in which channel they rather purchase apparel. In a five-point Likert-scale they were required to give a tendency three times; between online and stationary, online and mobile as well as mobile and stationary purchase channel. The first scale ranges from "1" representing "online" to "5" representing "stationary". The second scale ranges from " 1 " representing "online" to " 5 " representing "mobile", whereas the third scale ranges from "1" representing "mobile" to " 5 " representing "stationary". Mean responses for the channel variables are detailed in table 1, revealing that participants tend to purchase rather stationary than online $(M=3.5538)$, rather online than mobile $(M=1.9846)$ and rather stationary than mobile $(M=4.3231)$. These results indicate, that participants tend to purchase apparel primary in stationary channel, secondly online, followed by the mobile channel.

Table 1: Purchase Channels

\begin{tabular}{|l|r|r|r|r|r|}
\hline & \multicolumn{1}{|c|}{ N } & \multicolumn{1}{c|}{$\begin{array}{c}\text { Mini- } \\
\text { mum }\end{array}$} & \multicolumn{1}{c|}{$\begin{array}{c}\text { Maxi- } \\
\text { mum }\end{array}$} & Mean & $\begin{array}{c}\text { Std. Deviati- } \\
\text { on }\end{array}$ \\
\hline Online- & 65 & 2,00 & 5,00 & 3,5538 &, 91908 \\
stationary & 65 & 1,00 & 5,00 & 1,9846 &, 99204 \\
Online-mobile & 65 & 2,00 & 5,00 & 4,3231 &, 86797 \\
$\begin{array}{l}\text { Mobile- } \\
\text { stationary }\end{array}$ & 65 & & & & \\
Valid N & & & & \\
\hline
\end{tabular}


In order to find out more precisely in which channels participants purchase apparel, seven purchase groups were defined on the basis of their selected scales as follows: Online-stationary, online-mobile, mobile-stationary, online-stationary-mobile, online, stationary and mobile. The majority of participants $(N=43,66.2 \%$ of sample) purchase apparel in both online and stationary channel, while $10.8 \%(N=7)$ of the participants neither prefer one nor two purchase channel. Those who purchase only via one channel represent the minority with $15.4 \%$. $12.3 \%(N=8)$ of the participants purchase offline, $3.1 \%(N=2)$ online while none of the participants purchases apparel only via mobile.

Table 2 shows how important each purchase aspect for participants in general is (without considering the purchase channels). Participants were conducted to rate their degree of importance in a five-point Likert-scale, ranging from " 1 " representing "very important" to " 5 " representing "completely unimportant". Due to limitation in scope, only the most significant findings will be explained. With a mean value of 1.3231 , "design" tends to be the most important purchase aspect for participants.

Table 2: Importancy of purchase aspects in general

\begin{tabular}{|l|r|r|r|r|r|}
\hline & \multicolumn{1}{|c|}{$\mathrm{N}$} & Minimum & $\begin{array}{c}\text { Maxi- } \\
\text { mum }\end{array}$ & Mean & $\begin{array}{c}\text { Std. } \\
\text { Deviation }\end{array}$ \\
\hline Price & 65 & 1,00 & 4,00 & 2,0769 &, 66867 \\
Design & 65 & 1,00 & 3,00 & 1,3231 &, 56202 \\
Comfort & 65 & 1,00 & 4,00 & 2,0615 &, 72623 \\
Fit & 65 & 1,00 & 3,00 & 1,5846 &, 60962 \\
Origin & 65 & 1,00 & 5,00 & 3,2615 &, 98864 \\
Quality & 65 & 1,00 & 3,00 & 2,1692 &, 74097 \\
Production & 65 & 1,00 & 5,00 & 3,3846 &, 97935 \\
Social aspect & 65 & 1,00 & 5,00 & 2,8462 & 1,07864 \\
Quality seal & 65 & 1,00 & 5,00 & 3,5692 &, 95147 \\
Trend & 65 & 1,00 & 5,00 & 2,4462 &, 86658 \\
\hline
\end{tabular}

While this aspect is very important for the online-mobile purchase group $(N=3,100 \%)$, it is only partially important for those participants who purchase solely online $(N=2,100 \%)$. "Fit" $(M=1.5846)$ tends to be the second most important aspect for participants followed by "comfort" $(M=2.0615)$. Regarding sustainable purchase aspects, "quality" tends to be most important aspect $(M=2.1692)$. While "social aspects" tend to be partially important $(M=2.8462)$ to the average, for $37.2 \%(N=16)$ of online-stationary purchaser that aspect is more important. "Origin" $(M=3.2615)$ and "production" $(M=3.3846)$ tend to be partially important. For all $(N=2)$ mobile-stationary purchaser "production" is even completely unimportant. The most unimportant purchase aspect is "quality seal" for both the average of participants $(M=3.5692)$ and for the majority of the different purchase channels. These results indicate that general aspects for purchasing apparel are more important to participants of this study than sustainable aspects. There are also conflicting results within the purchase groups (the degree of importance).

Participants were also asked to answer in which channel they search for information regarding apparels (with the possibility of multiple responses). Nearly $90 \%$ of $(N=58,89.2 \%)$ participants search online for information, while $33.8 \%(N=22)$ search in stores and only $18.5 \%(N=12)$ via mobile. To examine further how the information and purchase channels relate to each other a multiple response cross tabulation was used. More than $70 \%$ $(N=41)$ of those participants who researched online, purchase either online or stationary, $10.3 \%(N=6)$ by all channels and $8.6 \%$ $(N=5)$ purchase only in stores. The half of those participants, who searched for information in stores as well as via mobile, purchased afterwards either online or in stores. $22.7 \%(N=5)$ of the stationary researchers purchase in all channels or similarly only in stationary retail. $16.7 \%(N=2)$ of those participants who researched information via mobile purchased either onlinemobile or similarly only in stores. Overall this implies that the majority of participants search online for information, while they purchase mainly in stores.

A paired samples (dependent) t-test was conducted to compare the consumers' degree of importance for information searching regarding sustainable aspects in general (without QR-code) and with a QR-code. In a five-point Likert-scale participants were asked to rate the degree of importance, ranging from "1" representing "very important" to " 5 " representing "completely unimportant". A one-tailed paired samples $t$-test:

- reveals that the degree of importance for information search of "origin" with a QR-Code $(M=2.3231, \mathrm{~s}=.93721)$ is higher than without a QR-Code $(M=3.0, \mathrm{~s}=1.01550), t(64)=$ $6.720, p=.000, \alpha=.05$

- reveals that the degree of importance for information search of "production" with a QR-Code $(M=2.5077$, $\mathrm{s}=1.04766)$ is higher than without a QR-Code $(M=3.0154$, $\mathrm{s}=.99204), t(64)=4.219, p=.000, \alpha=.05$

- reveals that the degree of importance for information search of "social aspects" with a QR-Code $(M=2,3231$, $\mathrm{s}=1,01716)$ is higher than without a QR-Code $(M=3,0462$, $\mathrm{s}=.97517), t(64)=6,530, p=.000, \alpha=.05$

- reveals that the degree of importance for information search of "quality" with a QR-Code $(M=1,6923, \mathrm{~s}=, 63549)$ is higher than without a QR-Code $(M=1,9231, \mathrm{~s}=, 69164)$, $t(64)=2,650, p=.005, \alpha=.05$

- reveals that the degree of importance for information search of "price calculation" with QR-Code $(M=2,7231$, $\mathrm{s}=1,17935)$ is higher than without a QR-Code $(M=3,6923$, $\mathrm{s}=1,01432), t(64)=6,906, p=.000, \alpha=.05$

- reveals that the degree of importance for information search of "quality seal" with a QR-Code $(M=3,1231$, $\mathrm{s}=, 96027)$ is higher than without a QR-Code $(M=3,4923$, $\mathrm{s}=, 88606), t(64)=4,017, p=.000, \alpha=.05$

These findings are significant as they reveal that, transparency through the application of a QR-Code in stores positively influences the consumers' perception of sustainability.

In order to explore the preference for a product with detailed information on the consumers' degree of importance for sustainable aspects, an independent $t$-test was used. This test found that:

- there was no statistically significant difference between searching for "product information" with a QR-Code of those who prefer a product with detailed information $(M=1.6667$, $\mathrm{s}=.76594)$ to those participants who do not prefer a product with detailed information $(M=1.6429, \mathrm{~s}=.49725), t(63)=.110$, $p=.913, \alpha=.05$

- there was a statistically significant difference in searching for information regarding "origin" with a QR-Code, $t(63)=2.880, p=.005, \alpha=.05$. The effect size for this analysis $(d=.927)$ was found to exceed Cohen's (1988) convention to a large effect $(d=.80)$. These results indicate that participants in the "preference" group $(M=2.1569, \mathrm{~s}=.92461)$ experienced higher importance regarding "origin" than did participants in 
the "non-preference" group $(M=2.9286, \mathrm{~s}=.73005)$ (see table 3)

- there was a statistically significant difference in searching for information regarding "production" with a QR-Code, $t(63)=3.025, p=.004, \alpha=.05$. The effect size for this analysis $(d=.867)$ was found to exceed Cohen's (1988) convention for a large effect $(d=.80)$. These results indicate that participants in the "preference" group $(M=2.3137, \mathrm{~s}=.94848)$ experienced higher importance regarding production than did participants in the "non-preference" group $(M=3.2143, \mathrm{~s}=1.12171)$.

- there was no statistically significant difference between searching for information regarding "social aspects" with a QR-Code of those who prefer a product with detailed information $(M=1.6078, \mathrm{~s}=1.00625)$ to those participants who do not prefer a product with detailed information $(M=2.7143$ $\mathrm{s}=.99449), t(63)=1.646, p=.105, \alpha=.05$

There was a statistically significant difference in searching for information regarding "quality" with a QR-code, $t(63)=2.099$, $p=.040, \alpha=.05$. The effect size for this analysis $(d=.61)$ was not found to exceed Cohen's (1988) convention $(d=.80)$. These results indicate that participants who prefer a product with detailed information $(M=1.6078, \mathrm{~s}=.60261)$ had statistically significant higher degrees of importance of searching for information than those participants who do not prefer a product with detailed information $(M=2.000, \mathrm{~s}=.67937)$.

Table 3: Preference for a Product with Detailed Information \& Information Search for Sustainable Aspects with QR-Code

\begin{tabular}{|c|c|c|c|c|c|}
\hline & 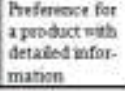 & $\mathrm{x}$ & Mean & $\begin{array}{l}\text { Sid Devia. } \\
\text { tion }\end{array}$ & $\begin{array}{l}\text { Std Emor } \\
\text { Mean }\end{array}$ \\
\hline \multirow{2}{*}{$\begin{array}{l}\text { Infomsation beasth prodact info with } \\
\text { QR.Code }\end{array}$} & ne & 14 & 1,6429 & .49725 & .1939 \\
\hline & yes & 51 & 16667 & 765904 & 10725 \\
\hline \multirow{2}{*}{$\begin{array}{l}\text { Infomsation vearth wiges with OR. } \\
\text { Code }\end{array}$} & at & 14 & 29285 & 73005 & 19511 \\
\hline & ses & 11 & 2.1569 & 92461 & 12947 \\
\hline \multirow{2}{*}{$\begin{array}{l}\text { Tnfomatinn weasch productios with } \\
\text { QR. Code }\end{array}$} & ne & 14 & 3,2143 & 1.12171 & 29979 \\
\hline & yes & 31 & 23137 & 94848 & 13331 \\
\hline \multirow{2}{*}{$\begin{array}{l}\text { Information search socal apects weth } \\
\text { QR-Codt }\end{array}$} & $\mathrm{as}$ & 14 & 2,7143 & 99449 & 26519 \\
\hline & ya & 51 & 16078 & 100525 & 14050 \\
\hline \multirow{2}{*}{$\begin{array}{l}\text { Infoussation search quality werh Q8. } \\
\text { Code }\end{array}$} & ne & 14 & 20000 & 67937 & .18127 \\
\hline & $y=$ & 31 & 1,6078 & 60262 & .08438 \\
\hline \multirow{2}{*}{$\begin{array}{l}\text { Information nearch packagingwith } \\
\text { QR.Code }\end{array}$} & no & 14 & 32857 & 772627 & 19410 \\
\hline & Yes & 31 & 3,0392 & 93725 & 13124 \\
\hline \multirow{2}{*}{ 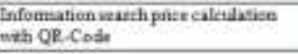 } & ae & 14 & 2,9286 & 1,14114 & 30458 \\
\hline & yes & 51 & 20067 & 1,19443 & 16723 \\
\hline \multirow{2}{*}{$\begin{array}{l}\text { Infomstion uasth quality wal with } \\
\text { QR. Code }\end{array}$} & RE. & 14 & 1,3571 & 22571 & 24223 \\
\hline & xen & 31 & 30588 & 96271 & 13551 \\
\hline \multirow{2}{*}{$\begin{array}{l}\text { Infoumation seazch wath and care lia- } \\
\text { bels with QR-Code }\end{array}$} & ne & 14 & 157914 & 51355 & 13725 \\
\hline & $y a$ & 31 & 13822 & 81602 & 11427 \\
\hline
\end{tabular}

These findings suggest that the preference for a product with detailed information perceived by participants has a positive influence on searching for information regarding "origin", "production" and "quality".

A chi-square test was performed to examine the relationship between the preference for a product with detailed information and the impacts on participants' perception of sustainability. The only statistically significant relationship was found between the preference for a product with detailed information and "positive shopping feeling", $x^{2}(1, N=65)=5,849, p=.016$. The effect size for this finding, Phi, was medium (.300). All other relationship have not shown a significant relation. These results indicate that there is a positive relationship between participants who prefer a product with detailed information to their perception of a "positive shopping feeling" caused by transparency via a QRcode $(\mathrm{N}=33$, more than half of the participants).

Participants were also asked to answer whether they purchase sustainable clothing and whether they used a QR-code in stores in order to search for information. One participant $(1.5 \%)$ purchased sustainable clothing only, while five (7.7\%) seldom and six (9.2\%) never purchased sustainable clothing. Almost half $(\mathrm{n}=5,45.5 \%)$ of those participants who used a QR-code before $(\mathrm{n}=11,16.9 \%)$ were not sure whether they purchased sustainable clothing or not, which represent in total 31 participants $(47.7 \%)$.

\subsection{Summary of the empirical findings}

The purpose of this study was to test the impact of transparency on perception of sustainability through the application of a QRCode in stores. According to the first research question, information regarding "origin", "production", "social aspects", "quality", "price calculation" and "quality seal" were rated of higher importance by participants through the application of a QR-code than without. The participants' degree of importance toward "price calculation" in general $(M=3.6923)$ and through the application a QR-code $(M=2.7231)$ displayed the most significant difference. These findings are noteworthy as they reveal that, transparency through the application of a QR-Code in stores positively influences the consumers' search for information. Regarding the second research question, the degree of importance for the sustainable aspects "origin" $(M=2.157)$, "production" $(M=2.3137)$ and "quality" $(M=1.6078)$ were rated higher by participants who prefer a product with detailed information. These findings suggest that there is a statistically significant difference between searching for information regarding "origin", "production" as well as "quality" and those participants who prefer a product with detailed information. According to the third research question, nearly $90 \%$ of the participants who perceive a "positive shopping feeling" through transparency via QR-Code prefer a product with detailed information. These findings are noteworthy, as they indicate that there is no statistically significant relationship between "credibility and trust", "higher awareness of purchasing sustainable clothing", "purchasing rather a product with detailed information", "purchasing additional products" as well as "willingness to pay a higher price" and preference for a product with detailed information.

In this study participants expressed that a product with detailed information is more attractive to them, but more than $80 \%$ did not use a QR-code in stores before. Moreover, participants perceive a positive shopping feeling through transparency via a QR-code. Further, information regarding sustainable aspects through a QR-code has been rated of high importance by participants. This is why retailers have to consider providing more detailed information for consumers.

\section{Discussion}

The previous chapters have shown that consumers have a lack of knowledge concerning sustainability. It is therefore important that companies provide detailed information so that consumers are able to make better buying decisions and finally have more confidence for purchasing sustainable products (Shen et al., 2012). Other findings indicated consumers conflicting perceptions of sustainability depending on the respondent sampling group. Therefore, companies have to know their target group and understand its needs and values (Thieme, 2015).

Technological developments lead to changing consumer behavior and retail environment. Still the majority of online shops have not implemented any omni-channel-services yet. However, consumers expect these since e.g. through click \& collect further impulse buying is possible. Nevertheless, approximately one 
third of these retailers are planning to implement omni-channelservices (EHI Retail Institute, 2015). Both ROPO and omnichannel-services have demonstrated how strongly offline and online channels influence one another. Especially when searching for information, the combination of using a smartphone at the POS plays an important role. The new buying-decision process illustrates how important the POD becomes as information is being provided through the internet (Heinemann \& Gaiser, 2015). This further indicates the importance of integrating different channels.

As findings regarding the fTRACE app indicated, traceability until a precisely defined region (Verbraucherzentrale Hamburg, 2015 , p.5) as well as a consistently labeled product range has not been taken into consideration yet. As literature has shown, it is important for companies to provide correct and trustworthy information which are available at POS and communicated in a comprehensible way (Confino, 2014). Transparency should not only be considered as a liability or marketing tool (Young, 2013). It should be correct and objective (Niinimäki, 2015). By the means of best-practice-examples, it has been shown that transparency is achievable across the whole supply chain e.g. through sharing a full cost breakdown. However, more than $90 \%$ of brands don not know where their raw materials come from, not to mention where their clothes are being produced (61\%) (Gould, 2014). Furthermore, there is still need for action as many companies pretend to be sustainable, but do not do any appropriate activities in this field, focusing more on economic aspects in order to maximize profit (Payton, 2013). It has been noted that sustainable engagement is more successful in the long run, since it builds trust and credibility among consumers (Niinimäki, 2015). As literature has demonstrated consumers increasingly ask for detailed information (Liegl, 2014). Therefore the fashion fTRACE app can be helpful to satisfy the consumers' demand for detailed information by combining sustainability and traceability with mobile technology at one place. However, there is need for improvements since many apps have technical problems, e.g. not having correct information ready. Providing trustworthy information through apps will help towards better buying decisions as well as an improved competitive factor, as they link several channels with each other (GS1, 2011; SchrammKlein et al., 2014).

The findings of the online questionnaire have demonstrated that, through the usage of a QR-code in stores, consumers give "origin", "production", "social aspects", "quality", "price calculation" and "quality seal" a higher importance while searching for information than without a QR-code. Especially concerning "price calculation" the difference between the information searching in general (without a QR-code) and with a QR-code has been huge and rated much higher than without a QR-code. Referring to the findings, transparent companies have shared a full cost breakdown of their products. This shows that they already perceive and consider the consumers' need for providing detailed information. Another finding in this research paper has shown that aspects such as price, availability or consumer ratings have been ranked higher than sustainable aspects. Therefore, other factors for information searching have to be taken into consideration as well. Consumers, who prefer a product with detailed information, have given "origin", "production" and "quality" a higher rating. This is crucial, since other findings in this research paper have also shown the preference for a product with detailed information. Another important finding demonstrated, that almost all of the participants who perceive a positive shopping feeling through transparency via a QR-Code agreed to prefer a product with detailed information. This finding is noteworthy since consumers benefit from a greater shopping experience, flexibility and simplicity while switching between channels back and forth (Heinemann \& Gaiser, 2015). However, the majority of participants have not used a QR-code in stores yet. This could have many reasons such as limited promotion or lack of attractiveness of existing QRcodes. Nevertheless, other findings in this paper have shown that the majority already used their smartphones for product information searches at the POS in 2014. Therefore, retailers have to consider providing more detailed information in form of a QR-code, as consumers change their information searching behavior and smartphones become more important during the buying-process.

Referring back to the specific research objective to investigate the relationship between consumers' perception of sustainability and the application of a QR-code in stores, with the focus on consumers' information searching behavior regarding sustainable aspects, a clear answer can be derived. There is a positive relationship, because consumers perceive sustainable aspects as much more important when detailed information is being provided through a QR-code such as the fashion fTRACE app. However, concerning the survey there was no statistically significant relationship between the participants who prefer a product with detailed information and other impacts on consumers' perceptions such as "willingness to pay a higher price" or "purchasing additional products". Nevertheless, other findings in this research paper have shown that consumers are willing to pay a higher price and in general have a positive attitude toward sustainable products as well as want to support sustainable practices. Therefore, companies have to provide detailed information so that consumers have more confidence to purchase sustainable clothes. Since, consumers search for product information through their smartphone and the sales volume of stationary retail is expected to decrease during the next years, QR-codes are a chance for retailers to hold not only consumers in the stationary retail, but also to link several channels with each other so that consumers do not switch to another one of a competing retailer. Through providing detailed product information, companies are able to build a connection between consumers and the purchased product so that they perceive the value of a product differently. Subsequently, an increased awareness of sustainability among consumers can be achieved. It is therefore important for retailers to focus on the consumers' needs and demand for purchasing via different channels.

\section{Conclusion}

The purpose of this paper was to critically reflect the relationship between consumers' perception of sustainability and the application of a QR-code in stationary fashion retail, with the focus on consumers' information searching behavior regarding sustainable aspects.

The results of the literature review reveal that consumers generally have a positive attitude toward sustainability and want to support sustainable fashion businesses, but they have a lack of knowledge about sustainable issues. It has been shown that both the sales volume of the online and mobile commerce is expected to increase rapidly during the next years, which represent the consumers' demand for purchasing in different channels. Since they also welcome omni-channel-services companies have to link their channels to each other. It has been demonstrated that consumers research online before purchasing offline, which results in a shift from the classical buying-decision process 
toward a new online buying-decision process due to extensive information provided through the internet. Further, consumers use their smartphone for product information searching at the POS. As the findings indicated, provided information needs to be correct, available at any time and trustworthy as well as communicated in such a way that consumers understand the company's purpose. It is further revealed that all stakeholders as well as a company's corporate culture have to be integrated holistically in the process of traceability in order to enable greater transparency along the supply chain. With the aid of technology such as RFID or Blockchain products can be identified along the value chain and therefore strengthen a higher level of transparency as well. But this engagement has to be true, longlasting and objective in order to be perceived as credible and trustworthy by consumers. It has demonstrated that a fashion fTRACE app can be helpful to satisfy the consumers' needs and their demand for detailed information. Key findings of the conducted online questionnaire are that those participants who prefer a product with detailed information perceive a positive shopping feeling through transparency via a QR-Code in stores. "Origin", "production" and "quality" were rated of higher importance by those participants. Comparing the information searching behavior of sustainable aspects, consumers give mostly all aspects a higher importance with a QR-code than without one. Especially the difference concerning "price calculation" has been prominent and rated much higher with a QR-code. These findings suggest that, transparency as established through the application of a QR-Code in stores influences the consumers' perception of sustainability.

Finally, this paper has limitations in the regard that it only focuses on the consumers' information searching behavior regarding sustainable aspects. Further research in both regards the literature review and the conducted survey is recommended to explore other factors impacting consumers' perception of sustainability. For instance, in this paper the consumers' buying behavior and its purchase aspects was not researched in detail. In order to understand the need of the sustainable consumer, further research should also examine the impact perceived by this target group. Due to the small sample size of 65 fashion students participating in the study findings are not generalizable to a larger population. Therefore it is also recommended that this study is expanded to a larger population.

After examining the findings of this research paper, it can be concluded that it becomes more and more difficult for companies to remain competitive without considering the integration of several channels. Consumers are still skeptical toward a company's sustainable activities due to misleading information or negative experiences in the fashion industry. For this reason, transparency can be only perceived as credible and trustworthy by consumers, if provided information is reliable, long-lasting and objective as well as communicated in a comprehensible way. Further, sustainable practices have to be implemented holistically in a company's corporate culture. A fashion fTRACE app can be therefore helpful to ensure greater transparency along the supply chain.

\section{References}

1. Allwood, J. M. (2006). Well dressed?: The present and future sustainability of clothing and textiles in the United Kingdom. Cambridge: University of Cambridge, Institute for Manufac-turing.

2. Bhaduri, G., \& Ha-Brookshire, J. E. (2011). Do Transparent Business Practices Pay?: Explo-ration of Transparency and
Consumer Purchase Intention. Clothing and Textiles Research Journal, 29(2), 135-149. doi:10.1177/0887302X11407910, CrossRef

3. Borromeo, L. (2013). Will transparency in the fashion industry ever become a reality? Retrie-ved from http://www.theguardian.com/sustainable-business/transparencyfashion-industry-reality, 9.1.2016

4. Bruce, A. (2012). Multi-Channeling der Zukunft: Multi-ChannelErfolgsfaktoren im wach-senden Markt aus Sicht von Google. In G. Heinemann, M. Schleusener, \& S. Zaharia (Eds.), TextilWirtschaft. Modernes Multi-Channeling im Fashion-Handel. Konzepte, Erfolgsfaktoren, Praxisbeispiele (pp. 50-72). Frankfurt am Main: Deutscher Fachverlag.

5. Carew, A. L., \& Mitchell, C. A. (2002). Characterizing undergraduate engineering students' understanding of sustainability. European Journal of Engineering Education, 27(4), 349-361. doi:10.1080/03043790210166657, CrossRef

6. Cohen, J. (1988). Statistical power analysis for the behavioral sciences (2. ed.). Hillsdale, NJ: Erlbaum, CrossRef

7. Confino, J. (2014). Can barcodes make fashion more transparent and will consumers care? Retrieved from http://www.theguardian.com/sustainable-business/fashioncompanies-sustainability-barcode-clothing-labels

8. Dickson, M. A. (2000). Personal Values, Beliefs, Knowledge, and Attitudes Relating to Intentions to Purchase Apparel from Socially Responsible Businesses. Clothing and Textiles Research Journal, 18(1), 19-30. doi:10.1177/0887302X0001800103, CrossRef

9. Drexhage, J., \& Murphy, D. (2010). Sustainable Development: From Brundtland to Rio 2012. New York.

10. ECC Köln. (2015). E-Commerce 2015 - Wie wir wirklich online einkaufen: Eine internetre-präsentative Studie des ECC Köln zum 20-jährigen Jubiläum von otto.de. Köln. Retrieved from http://www.ecckoeln.de/PDFs/2015/E-

Commerce2015_Wiewirwirklichonlineeinkaufen_Web.pdf, 12.1.2016

11. ECC Köln \& hybris GmbH. (2014). Cross-Channel 2020 - Smart Natives im Fokus: Ein Whi-tepaper des E-Commerce-Center Köln (ECC Köln) in Zusammenarbeit mit der hybris GmbH. Retrieved from

http://www.ecckoeln.de/Downloads/Themen/Zielgruppen/ECCKln_ Whitepaper_Cross-Channel2020_SmartNativesimFokus_2014.pdf, 12.1.2016

12. EHI Retail Institute. (2015). Wie der Onlinehandel stationäre Läden beflügelt $\quad$... $\quad$ Retrieved from https://www.ehi.org/de/pressemitteilungen/wie-der-onlinehandelstationaere-laeden-befluegelt/, 12.1.2016

13. EHI Retail Institute \& Statista GmbH. (2015). Onlinehändler mit vielen Touchpoints erfolg-reicher. Retrieved from https://www.ehi.org/de/pressemitteilungen/onlinehaendler-mitvielen-touchpoints-erfolgreicher/, 12.1.2016

14. Everlane. (n.d.). About. Retrieved from https://www.everlane.com/about, 10.1.2016

15. fashion fTRACE. (2015). Fashion Trace Code. Retrieved from http://fashionftrace.jimdo.com/startseite/fashion-trace-code/, 12.1.2016

16. Fletcher, K. (2008). Sustainable Fashion and Textiles: Design Journeys. London: Earthscan.

17. fTRACE. (2015a). about fTRACE. Retrieved from http://www.ftrace.com/en/gb/about, 12.1.2016

18. fTRACE. (2015b). fTRACE partners. Retrieved from http://www.ftrace.com/en/gb/partners, 12.1.2016

19. Gam, H. J., \& Banning, J. (2011). Addressing Sustainable Apparel Design Challenges with Problem-Based Learning. Clothing and Textiles Research Journal, 29(3), 202-215. doi:10.1177/0887302X11414874, CrossRef

20. Gehrckens, M., \& Boersma, T. (2013). Zukunftsvision Retail - Hat der Handel eine Daseins-berechtigung? In G. Heinemann, K. Haug, M. Gehrckens, \& dgroup (Eds.), Digitalisierung des Handels mit 
ePace: Innovative E-Commerce-Geschäftsmodelle und digitale Zeitvorteile (pp. 51-74). Wiesbaden: Springer Gabler.

21. Gould, H. (2014). Can the global fashion industry become transparent? Retrieved from http://www.theguardian.com/sustainable-business/sustainablefashion-blog/global-fashion-industry-become-transparent, 3.1.2016

22. GS1. (2011). Beyond the Label: Providing Digital Information Consumers Can Trust. Retrie-ved from https://www.capgemini.com/resource-file-

access/resource/pdf/Beyond_the_Label.pdf, 12.1.2016

23. GS1 Germany. (n.d.). The shopper rules: Influence of interest and smartphones on the infor-mation behaviour of consumers. A study on behalf of GS1 Germany carried out by Gfk (Ge-sellschaft für Konsumforschung - The Association for Consumer Research). Köln.

24. GS1 Germany. (2013). The shopper still rules: Die Nutzung von Smartphones und Internet im Informations- und Kaufprozess. durchgeführt von Gfk. Retrieved from https://www.gs1-germany.de/fileadmin/gs1/basis_informationen/erl_10042013_studie_the_s hopper_still_rules.pdf, 4.1.2016

25. Heinemann, G., \& Gaiser, C. (2015). SoLoMo - Always-on im Handel: Die soziale, lokale und mobile Zukunft des Shopping (2.th ed.). Wiesbaden: Springer Gabler, CrossRef

26. Hill Hyun-Hwa Lee, J. (2012). Young Generation Y consumers' perceptions of sustainability in the apparel industry. Journal of Fashion Marketing and Management: An International Journal, 16(4), 477-491. doi:10.1108/13612021211265863, CrossRef

27. Honest by. (n.d.). About. Retrieved from http://www.honestby.com/en/page/16/about.html, 3.1.2016

28. Howe, U. (2015). Totale Transparenz bei Macy's. Retrieved from http://www.textilwirtschaft.de/suche/show.php?src=40\&ids=308678 $\& \mathrm{a}=0,5.1 .2016$

29. INTERNET WORLD. (2015). Drei von vier Web-Käufern shoppen mehrmals pro Monat. Retrieved from http://www.internetworld.de/ecommerce/zahlen-studien/drei-vier-web-kaeufern-shoppenmehrmals-monat-999889.html, 5.1.2016

30. Jefremow, K. (2013). Wirtschafts- und Unternehmensethik: Wege zur Sicherung der Zu-kunftsfähigkeit von Unternehmen. Hamburg: Diplomica Verlag Gmbh.

31. Jimdo. (n.d.). Startseite. Retrieved from http://de.jimdo.com/, 5.1.2016

32. Joergens, C. (2006). Ethical fashion: myth or future trend? Journal of Fashion Marketing and Management: An International Journal, 10(3), 360-371. doi:10.1108/13612020610679321, CrossRef

33. Kozar, J. M., \& Hiller Connell, K. Y. (2013). Socially and environmentally responsible apparel consumption: Knowledge, attitudes, and behaviors. Social Responsibility Journal, 9(2), 315324. doi:10.1108/SRJ-09-2011-0076, CrossRef

34. Liegl, P. (2014). Rückverfolgung von Lebensmitteln mit Hilfe von fTRACE. Retrieved from https://ecosio.com/de/blog/2014/09/04/Rueckverfolgung-vonLebensmitteln-mit-Hilfe-von-fTRACE/, 5.1.2016

35. Meßing, F. (2014). Aldi gibt Informationen über Fleisch preis - aber nicht alle. Retrieved from http://www.derwesten.de/wirtschaft/aldigibt-informationen-ueber-fleisch-preis-aber-nicht-alleid9781988.html, 5.1.2016

36. Morton, A. (2015). A Sustainable Strategy: Transparency is Trending in the Fashion World. Retrieved from http://www.paceco.com/transparency-fashion-industry/, 12.1.2016

37. Niinimäki, K. (2010). Eco-clothing, consumer identity and ideology. Sustainable Develop-ment, 18(3), 150-162. doi:10.1002/sd.455, CrossRef

38. Niinimäki, K. (2015). Ethical foundations in sustainable fashion. Textiles and Clothing Sustainability, 1(1), 51. doi:10.1186/s40689015-0002-1, CrossRef

39. Payton, J. (2013). A sustainable model for fashion. Retrieved from http://www.theguardian.com/sustainable-business/sustainablemodel-for-fashion, 13.1.2016
40. Peruvian Connection. (2016). Produktinformationen: Peruanische Pimabaumwolle. Retrieved from http://www.peruvianconnection.de/category/produktinformationen/pi mabaumwolle.do, 5.1.2016

41. QR Code Generator. (2014). Startseite. Retrieved from http://www.qrcode-generator.de/, 1.11.2015

42. Radhakrishnan, S. (2015). The Sustainable Apparel Coalition and the Higg Index: Future Ac-tion Plans. In S. S. Muthu (Ed.), Roadmap to Sustainable Textiles and Clothing. Regulatory Aspects and Sustainability Standards of Textiles and the Clothing Supply Chain (pp. 23-58). Singapore: Springer, CrossRef

43. Reformation. (2015). Who we are. Retrieved from https://www.thereformation.com/about-us\#business, 15.12.2015

44. Reinartz, W. (2015). Digitalisierung und ihr Einfluss auf den Handel in Deutschland. Köln. Retrieved from http://www.bmwi.de/BMWi/Redaktion/PDF/W/workshopdigitalisierung-vortrag-digitalisierung-und-ihr-einfluss-auf-denhandel,property=pdf,bereich=bmwi2012,sprache $=$ de,rwb=true.pdf, 19.11.2015

45. Rittinger, S. (2014). Multi-Channel Retailing: Prinzip, Konzepte und Erfolgsfaktoren. Wies-baden: Springer Gabler, CrossRef

46. Schramm-Klein, H., Wagner, G., Neus, F., Swoboda, B., \& Foscht, T. (2014). (R)Evolution des Mehrkanalhandels: Von Multi-Channelüber Cross-Channel- zu Omni-Channel-Retailing (Neue Ausg). HandelsMonitor. Frankfurt am Main: Deutscher Fachverlag.

47. Shen, B., Wang, Y., Lo, C. K., \& Shum, M. (2012). The impact of ethical fashion on consu-mer purchase behavior. Journal of Fashion Marketing and Management: An International Journal, 16(2), 234245. doi:10.1108/13612021211222842, CrossRef

48. Shen, D., Richards, J., Lui, \& Feng. (2013). Consumers' Awareness of Sustainable Fashion. Marketing Management Journal, 23(2), 134147.

49. Solomon, M. R., \& Rabolt, N. J. (2004). Consumer behavior in fashion. Upper Saddle River, N.J: Prentice Hall.

50. Spannuth, L. (2012). Integriertes Multi-Channeling als strategische Chance: Multi-Channel aus Sicht des mittelständischen Traditionshändlers Schuh Görtz. In G. Heinemann, M. Schleusener, \& S. Zaharia (Eds.), TextilWirtschaft. Modernes Multi-Channeling im Fashion-Handel. Konzepte, Erfolgsfaktoren, Praxisbeispiele (pp. 127-141). Frankfurt am Main: Deut-scher Fachverlag.

51. Steiner, J. (2015). Op-Ed I Blockchain Can Bring Transparency to Supply Chains. Retrieved from http://www.businessoffashion.com/community/voices/discussions/do es-made-in-matter/op-ed-blockchain-can-bring-transparency-tosupply-chains, 19.12.2015

52. Thieme, S. (2015). Sustainable fashion - movement in the fashion market? Retrieved from http://blog.gfk.com/2015/10/sustainablefashion-movement-in-the-fashion-market/, 19.12.2015

53. Thøgersen, J., \& Schrader, U. (2012). From Knowledge to ActionNew Paths towards Sustainable Consumption. Journal of Consumer Policy, 35(1), 1-5. doi:10.1007/s10603-012-9188-7, CrossRef

54. Thomas, J. S., \& Sullivan, U. Y. (2005). Managing Marketing Communications with Mul-tichannel Customers. Journal of Marketing, 69(4), 239-251. doi:10.1509/jmkg.2005.69.4.239, CrossRef

55. T-Systems. (2013). Cross-Channel-Retailing: Die Zukunft des Handels. Dresden.

56. Venkatesan, R., Kumar, V., \& Ravishanker, N. (2007). Multichannel Shopping: Causes and Consequences. Journal of Marketing, 71(2), 114-132. doi:10.1509/jmkg.71.2.114, CrossRef

57. Verbraucherzentrale Hamburg. (2015). Stichprobe: Rückverfolgbarkeit von Zutaten für Le-bensmittel. Retrieved from http://www.vzhh.de/ernaehrung/407119/vzhh_Rueckverfolgbarkeit_ von\%20_Lebensmitteln_20150903.pdf, 12.12.2015

58. Williams, K. C., \& Page, R. A. (2011). Marketing to the generations. Journal of Behavioral Studies in Business, 5(1), 1-17.

59. Young, R. (2013). Stripped Bare: Brands Move Toward Transparency and Traceability. Ret-rieved from 
http://www.businessoffashion.com/articles/intelligence/nike-nudiehonest-by-bruno-pieters-stripped-bare-brands-move-towardtransparency-and-traceability, 5.1.2016

60. Zady. (2015). Our Mission. Retrieved from https://zady.com/thenewstandard/our-mission, 15.11.2015

61. Zaharia, S. (2012). Channel-Hopping erfordert integrierte MultiChannel-Lösungen: Wie die Kunden sich verhalten und wie die deutschen Top-Multi-Channel-Textilhändler darauf ant-worten. In G. Heinemann, M. Schleusener, \& S. Zaharia (Eds.), TextilWirtschaft. Modernes Multi-Channeling im Fashion-Handel. Konzepte, Erfolgsfaktoren, Praxisbeispiele (pp. 29-49). Frankfurt am Main: Deutscher Fachverlag. 